\title{
MASCARADAS E "DES(MAS)CARADAS": UM ESTUDO ACERCA DAS REPRESENTAÇÕES DE GÊNERO EM MANIFESTAÇÕES CARNAVALESCAS EM PORTUGAL E NO BRASIL
}

Maskeds and "(Un)maskeds": A Study About Gender Representations in Carnival Manifestations in Portugal and Brazil

ANDRADE, Priscila; Mestre; PUC-Rio

priscila.a.andrade@puc-rio.br

FORMIGA, Simone; Doutora; PUC-Rio

simone.formiga@infolink.com.br

GAMBA JUNIOR, Nilton; Doutor; PUC-Rio

gambajunior@gmail.com

\section{Resumo}

Este trabalho apresenta um estudo acerca da recente participação feminina em duas manifestações culturais com ligações históricas entre si e com os mascarados ibero-americanos: Caretos de Podence (Portugal) e Bate-bolas no Rio de Janeiro (Brasil). Até pouco tempo atrás, essas manifestações pertenciam apenas ao mundo masculino, por isso, fez-se necessário refletir sobre aspectos da construção da aparência das "brincantes" e de suas performances. A análise deste artigo se dá a partir da perspectiva da área do Design e busca, a partir das indumentárias, investigar como elementos formais acabam por estabelecer a visualidade do gênero feminino. A pesquisa demonstra como as mulheres, ao participarem dos rituais dos Caretos utilizando os fatos (trajes/fantasias) masculinos, acabam por "esconder" o gênero feminino. Por outro lado, verifica que as Bate-boletes vestem roupas que valorizam a visibilidade de seus corpos e não utilizam máscaras. Assim acabam por inserir uma "nova categoria", o gênero feminino que começa a ter visibilidade no mundo dos Bate-bolas.

Palavras Chave: gênero feminino; visibilidade; máscara e carnaval.

\section{Abstract}

This work presents a study about the recent female participation in two cultural manifestations with historical connections between themselves and with the ibero-americans maskeds: Caretos de Podence (Portugal) and Bate-bolas in Rio de Janeiro (Brazil). Until recently, these manifestations belonged only to the masculine world, therefore, it was necessary to reflect on aspects of the construction of the appearance of the people who "plays" carnival and their performances. The analysis of this article is based on from the perspective of Design and seeks to investigate how formal elements end up establishing the visuality of the female gender, taking the clothings as the point of departure. The research demonstrates how women, by participating in the rituals of Caretos using the masculine facts, end up "hiding" the feminine gender. On the other hand, it verifies that the Bate-boletes wear clothes that value the visibility of their bodies and do not use masks. In this way, they end up inserting a "new category", the feminine gender that begins to have visibility in the world of the Bate-bolas.

Keywords: feminine gender; visibility; mask and carnival. 
“A Máscara é um elemento que, temporal e espacialmente, conhece uma enorme representação e um universalismo que nenhum outro testemunho material da cultura humana iguala." Benjamim Enes Pereira

\section{0 contexto}

Este trabalho é parte de um projeto de pesquisa em Design sobre mascarados iberoamericanos da PUC-Rio, realizado pelo grupo de pesquisa do Laboratório Dhis - Design De Histórias, coordenado pelo professor Dr. Nilton Gamba Junior. Em 2016, o Dhis começou a formular o projeto em parceria com a Universidade Federal do Recôncavo Baiano, o Instituto Politécnico de Leria e a Faculdade de Belas-Artes da Universidade do Porto e ao qual os autores desse artigo têm colaborado desde o início. O projeto visa contemplar três festejos: os Caretos de Podence (Trás os Montes, Portugal), os Caretas (Recôncavo Baiano, Bahia, Brasil) e os Bate-bolas (periferia do Rio de Janeiro, Brasil) por conta de seus laços históricos de origem na tradição do mascarados iberoamericanos. Neste artigo, faremos um recorte nos festejos de Podence e do Rio de Janeiro.

São vários os enquadramentos de pesquisa dados ao material recolhido no campo e, neste artigo, destacamos a vertente que se detém nas questões de representação do gênero dos brincantes dos festejos. Para o desenvolvimento deste recorte, partimos do artigo apresentado no 1 o CIMODE, realizado em 2012 em Guimarães, Portugal, intitulado "As fôrmas da forma: um estudo da (des)configuração dos corpos português e brasileiro" (FORMIGA, 2012). No referido artigo, Formiga, trata de questões relacionadas à (des)configuração dos corpos português e brasileiro com ênfase nos corpos femininos. Conclui que enquanto o corpo português é invisível e, segundo Alexandre Melo, chega a ser inexistente - no que diz respeito às normas de apagamento propostas por quem busca o controle sobre a representação desse corpo; o corpo brasileiro possui valor de mercado, é passível de ser projetado, pode ser considerado um "objeto com design" e possui grande visibilidade.

Iniciamos, então, este recorte de pesquisa no qual buscamos investigar a participação das mulheres (portuguesas e brasileiras) em manifestações culturais carnavalescas. Até algum tempo, a participação feminina não era permitida no evento dos Caretos de Podence e era rara no evento dos Bate-bolas do Rio de Janeiro. Sendo assim, nosso objetivo principal é verificar a inserção do gênero feminino e a sua visibilidade/invisibilidade nas respectivas manifestações.

\section{Presença feminina entre os Caretos de Podence}

Os Caretos de Podence, também conhecidos como Entrudos Chocalheiros, são os personagens de uma performance tradicional que ocorre nessa aldeia, ao norte de Portugal. Podence pertence ao concelho de Macedo de Cavaleiros, distrito de Bragança, região de Trás os Montes, por onde ocorrem outros festejos semelhantes. Para situar sua origem, recorremos a dissertação de mestrado "Caretos de Podence: história, patrimônio e turismo", de Luís Felipe Rodrigues da Costa.

\footnotetext{
“De facto, não sabemos até onde podemos recuar e encontrar estes mascarados a agir tal como hoje agem e a vestir a indumentária que hoje vestem, sendo que a transmissão oral remete esta tradição para tempos mais recuados do que aqueles a que os registos escritos nos podem remeter neste momento." (COSTA, 2015, p. 7)
}

O festejo dos Caretos deve ser entendido "como o continuar de processos de transformações, fusões, mudanças, sincretismos, reformulações, adaptações, aculturações e persistências de fórmulas rituais e festivas de diversos povos que passaram pelo nordeste de Portugal."(COSTA, 2015, p. 8) Sua origem, comum a maior parte dos mascarados ibero-americanos, incluindo os Ba- 
te-bolas, remonta aos rituais pagãos que marcam a sazonalidade e o ciclo da agricultura. O festejo simboliza o fim do ciclo do inverno, quando as atividades agrícolas abrandam, e o início da primavera buscando através de rituais, restabelecer a fertilidade da terra e preparar para um novo ciclo de agrícola.

A grande festa de inverno, para o Homem das primeiras sociedades agrárias, seria, portanto, o momento do fim de um ciclo - mais tarde apelidada de fim do ano - e as emoções associadas aos rituais seriam de entusiasmo, euforia, excessos, licenciosidades, confusão social e a total ausência de regras morais de modo a recriar o "caos original". Mas seria também a festa de um novo ciclo - do novo ano - da ressurreição da terra que novamente ganha vida e trás abundância. Seria ainda a festa da purificação do Homem, que entra na primavera livre de todos os males, tal como era no momento da sua criação. (COSTA, 2015, p. 13)

Sendo assim, o nome Entrudo remete à entrada na primavera. Sobre a fertilidade, ainda segundo Costa, os povos indo-europeus, em geral, prestavam culto à terra, considerada a 'Mãe Geradora dos Homens'. Deste modo, a terra e a mulher, passaram a ter relação simbólica com a fertilidade (COSTA, 2015, p. 14).

Em 380 d.C., o imperador Teodósio I decretou o Édito de Tessalónica, onde estabelecia o Cristianismo como religião oficial em todo o Império Romano. (...)Durante o longo período de afirmação do cristianismo, os novos clérigos procuraram abolir ou reconverter as festas de origem politeísta. Embora dessacralizadas, as festas de ano novo continuavam a ter uma importância lúdica e simbólica, o que fez com que, em certas regiões, perdurassem como um costume, uma tradição. (COSTA, 2015, p. 21)

Assim, a festa acabou por ser incorporada ao calendário cristão e associada ao início da quaresma, que começa na quarta-feira de cinzas. Portando, além de estar associada ao ciclo da agricultura e a sazonalidade, refere-se também ao período de 40 dias no qual os cristãos devem observar penitência, caridade, jejum, abstinência sexual e oração para se preparar para celebrar a Páscoa, comemoração da ressureição de Cristo. Período que se manteve na migração dos festejos para as colônias ibéricas nas Américas. Porém, para ser paralelo ao calendário ibérico, no hemisfério sul, fica, então, deslocado do início da primavera - já que este período coincide com o início do outono abaixo do Equador.

Figura 1: Matrafonas
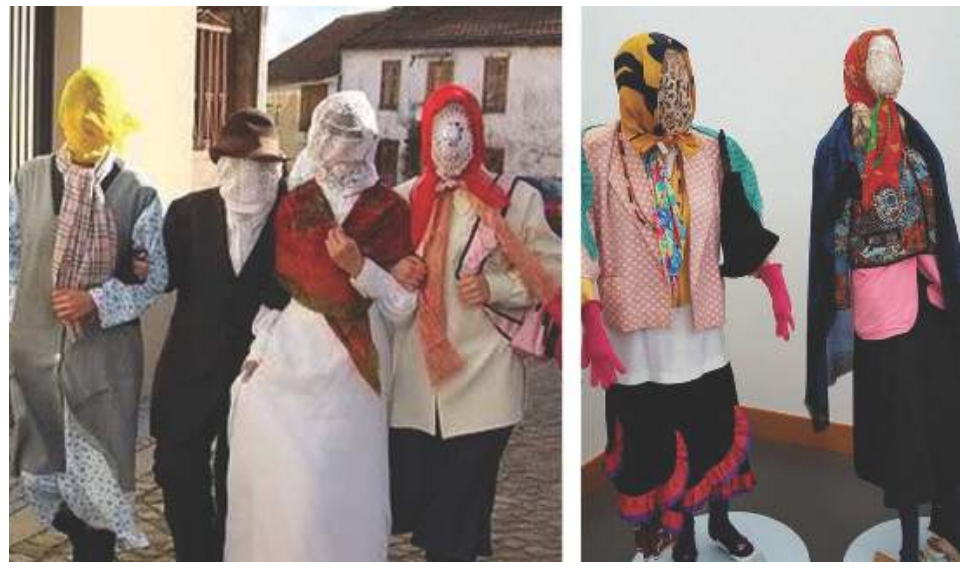

fonte: Da esquerda para a direita: http://diasquevoam.blogspot.com.br/2010/02/entrudo-chocalheiro-ou-os-caretosde.html e http://www.viajecomigo.com/2017/02/11/casa-do-careto-podence-macedo-de-cavaleiros/. 
Segundo Raposo, a região transmontana, interior de Portugal, foi por muito tempo isolada e por isso imune a influências externas, o que fez com que o festejo dos Caretos pudesse se manter cristalizado por tanto tempo. Porém, essa região predominantemente agrícola passou por mudanças socioculturais e econômicas que levaram à desertificação e ao êxodo migratório. (RAPOSO, 2006, p. 85-86). Isso, praticamente, provocou o completo desaparecimento do ritual nos anos 1960 e 1970. Então, em 1985, ele foi "renascido" pela Associação de Melhoramentos, Festas e Feiras que se ocupou de recuperar e promover a manifestação cultural. Fatos (trajes/fantasias) foram recuperados, novos foram confeccionados e assim o ritual do passado foi folclorizado ${ }^{1}$ revelado como um espetáculo. Segundo Raposo, a tradição foi cristalizada e apresentada como produto de arte étnica. As instituições de turismo, hoje, empregam um discurso de valorização das tradições de forma positiva. A imagem de uma aldeia arcaica e atrasada foi sendo esquecida ao passo que a festa foi atraindo mais turistas a cada ano.

De acordo com Tiza, os principais dias do festejo são o Domingo Gordo e a terça-feira, quando os Caretos saem às ruas com muita energia, reproduzindo seus movimentos característicos, ao som de gaitas de foles. Além dos Caretos, personagens masculinos, o Entrudo de Podence conta também com as Matrafonas, personagens femininos. Na terça-feira ocorrem as "cerimônias dos casamentos" sátiros, verdadeiros cortejos nupciais com a presença das Matrafonas ${ }^{2}$ junto com os Caretos (TIZA, 2018).

Estes personagens, típicos dos carnavais rurais são encarnados quer por jovens raparigas, quer por vezes também pelos rapazes. A sua fatiota consiste normalmente em usar a antiga indumentária domingueira das senhoras, com um lenço na cabeça e cobrindo a cara com uma renda. Estão imunes às chocalhadas dos Caretos, pelo que é comum que as raparigas da aldeia se vistam assim para os provocar, uma vez que se tornam num alvo inacessível. Quando encamadas pelos rapazes, criam uma imagem de ridicularização, pela inversão dos papéis de género e por um comportamento exagerado, ainda pelo uso desordenado do vestiário feminino, como o uso da lingerie por cima da roupa, por exemplo. (FERREIRA, 2016, p. 51)

Figura 2: Facanitos.
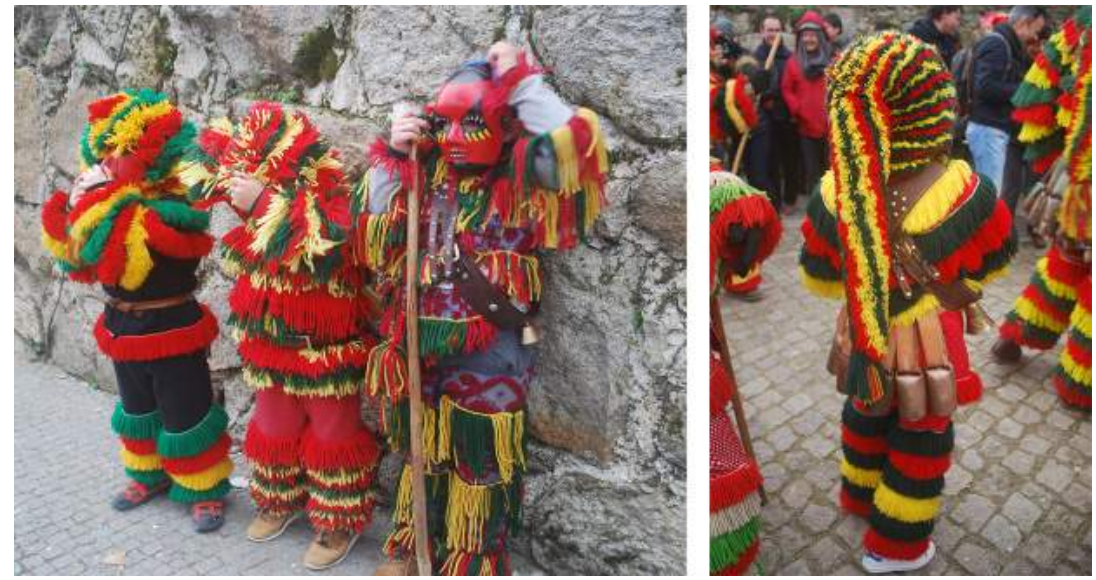

fonte: Simone Formiga (2018).

\footnotetext{
${ }^{1}$ Consideramos o termo foclorização como a ação de resgatar e fazer reviver uma manifestação cultural conforme sua existência prévia e mantê-la com as mesmas características.

${ }^{2}$ Também conhecidas por Marafonas ou Madamo/as.
} 
Se antigamente eram somente os rapazes solteiros que se vestiam de Caretos, uma vez que o ato de "chocalhar" simulava o acasalamento, nos dias de hoje, segundo Ferreira, não só os rapazes solteiros podem utilizar as fantasias, "é até muito incentivada a participação das crianças pequenas". Meninos, chamados de Facanitos, em sua grande maioria. Em nossas pesquisas de campo não encontramos meninas "Facanitas". Chegamos a conversar com alguns Facanitos e perguntamos para o quê serviam os chocalhos. A resposta: "Para chocalhar!". Tentamos ir mais além: "E sabes o que significa chocalhar?" Resposta: "Para brincar". Aqui podemos deixar uma questão em aberto para a continuação de nossa investigação: quando e de que forma os Facanitos, ou seja os meninos, começam a perceber a relação do ato de chocalhar com a representação da cópula?

Segundo, ainda Ferreira, "as crianças vestem fatos e máscaras similares aos dos Caretos e, desde cedo, vão fazendo de conta que chocalham e que posam para as fotografias, numa imitação muito literal do comportamento dos Caretos de hoje." (FERREIRA, 2016, p. 31).

Os Caretos vestem uma fantasia confeccionada, normalmente, a partir de uma colcha antiga, sobre a qual são aplicadas franjas de lã alternando as cores: verde, amarelo e vermelho, por todo o comprimento. Também a cabeça é coberta por um capuz com uma grande cauda igualmente coberta por franjas nas mesmas cores. Na cintura se fixam diversos chocalhos dependurados em um cinto de couro. No torço, cruzam-se duas bandoleiras de couro em que se prendem as campainhas (sinos).

A descrição que nos oferece dos Caretos de Podence é a de um mascarado que protagoniza o Diabo, com um comportamento bizarro, que assusta crianças, impõe respeito aos adultos e persegue as "raparigas mais incautas que teimam em vir à rua e que ele se as agarra, não deixa de abraçar ou, menos cortês, de tentar açoitá-las no sítio mais indicado - de tudo isto faz o Careto, que mesmo em pleno campo, quando se dirige de uma para outra aldeia, não deixa de correr, de saltar, de chocalhar, de descarregar golpes tremendos com a sua moca, como se estivesse em luta com um inimigo invisível, tal como decerto praticava, há dezenas de séculos, uma figura semelhante, cuja missão se esfumou no rodar do tempo." (FERREIRA apud PESSANHA, 2016, p. 19)

Figura 3: Trajes e máscaras.
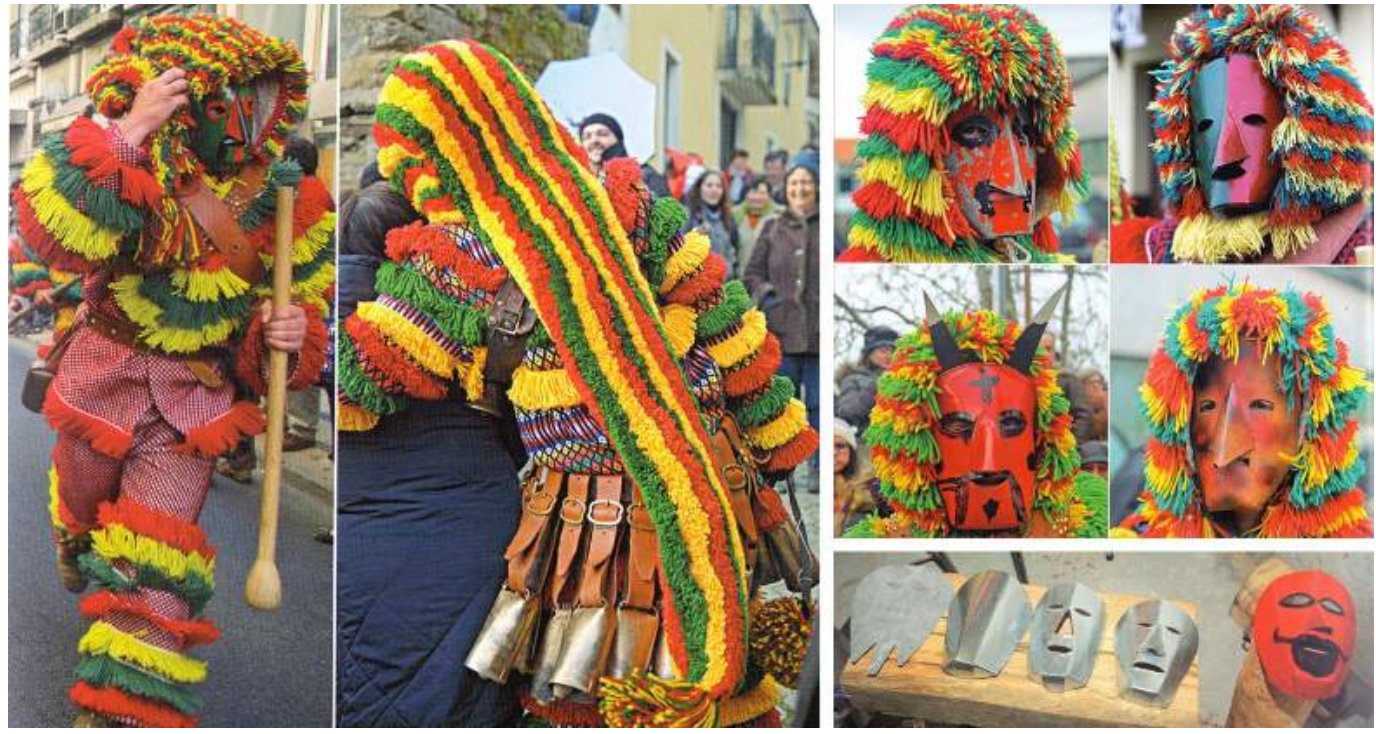

fonte: FERREIRA, 2016, p. 15, p. 36 e no canto inferior direito p. 34. 
No entanto, segundo Ferreira, "a participação das raparigas é relativamente tolerada embora muitos a entendam como um desvirtuamento do papel que ainda hoje se atribui aos Caretos e que não pode ser protagonizado por elas, as chocalhadas." (idem, p. 31). Porém, com a migração dos rapazes para o estrangeiro ou para as zonas urbanas em busca de oportunidades, as moças acabam por serem aceitas nos rituais. A contribuição feminina tornou-se importante para a continuidade da tradição, uma vez que colabora para o número de Caretos na festa. Ao mesmo tempo é um reflexo da contemporaneidade, quando a mulher passa a assumir papéis antes exclusivamente designados aos homens.

(...) A performance e o discurso da festa não parecem indicar que o género seja o assunto central. Todavia, toda a festa é organizada na base de uma divisão do trabalho que segue as linhas divisórias da idade e do género. A ordem do género é, assim, remetida para uma espécie de "infra-estrutura" não representada e não representável, o que, paradoxalmente, a naturaliza. Por isso seria lícito pensar que qualquer alteração no papel jogado pelas mulheres abalaria a ordem de género. Todavia, essa alteração, ao verificar-se, recentemente, no género de quem enverga as máscaras, deixa ainda essa alteração no domínio do extra-social (representado pelos mascarados), do absolutamente temporário, restrito à festa e não visível. (idem, p. 31)

Há poucas mulheres que se (trans)vestem de Caretos. Na pesquisa de campo realizada no Carnaval de 2018, só tivemos o conhecimento de uma brincante, apesar de encontrarmos imagens de outras mulheres (trans)vestidas de Caretos em carnavais recentes.

Figura 4: mulheres brincantes já documentadas em períodos anteriores e, à direita, a pesquisadora Simone Formiga com Sophie, a única mulher que se fantasiou de Careto em 2018.
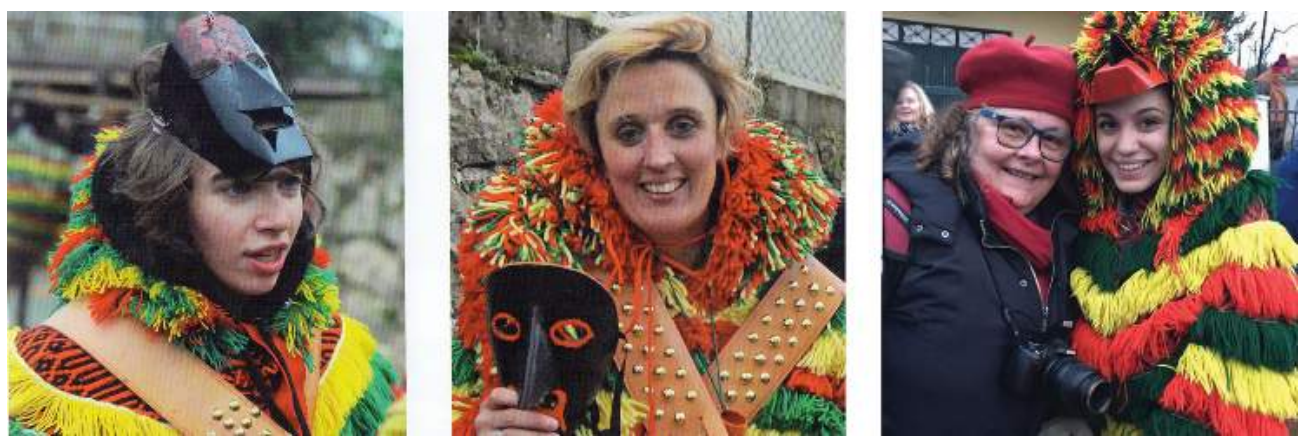

Fonte: FERREIRA, 2016, p. 31 e Gamba Junior, 2018.

\section{Os Bate-bolas e as Bate-boletes}

Os Bate-bolas e as Bate-boletes são personagens de uma manifestação urbana típica da periferia do Rio de Janeiro, região da cidade que é majoritariamente habitada por classes populares. Suas performances ocorrem também no período do carnaval e com fortes laços materiais e ritualísticos com a tradição dos mascarados ibero-americanos. No entanto, a preparação para o evento se dá ao longo dos meses que antecedem a data do festejo. Isso acontece por conta da exigência de ineditismo da fantasia anual e a complexidade de produção, tanto da fantasia quanto da performance. Por não circular por toda a cidade, a 'festa dos Bate-bolas', não é muito conhecida em outras regiões da própria cidade, como na Zona Sul, onde encontramos uma maior concen- 
tração das classes mais favorecidas economicamente. Definindo assim, não só uma separação regional, mas também de classe social. Porém, eles devem ser considerados personagens tradicionais do carnaval carioca.

De acordo com Aline Pereira, autora da dissertação "Tramas simbólicas: a dinâmica das turmas de bate-bolas do Rio de Janeiro"(PEREIRA, 2008), os foliões que deram origem aos Batebolas começaram a surgir nos anos 1930, na região de Santa Cruz, subúrbio do Rio de janeiro. A autora aponta dois fatos que podem ter colaborado para a origem de tal manifestação: o bairro sediava um matadouro que fornecia as bexigas de boi, acessório essencial para a fantasia, e também abrigou o hangar de um zepelim onde trabalhavam alguns militares alemães. Ainda segundo Pereira, a palavra Clóvis que, primeiro nomeou esses brincantes é uma corruptela de Clown, que significa palhaço em alemão, e era usada pelos estrangeiros para falar dos foliões que circulavam pela região na época do carnaval com sua indumentária característica. (PEREIRA, 2008, p. 24) Há registros de que inicialmente produziam fantasias isoladas composta por um macacão, capa, máscara e a bexiga de boi. Essa, era desidratada, inflada com ar, e amarrada numa corda, por sua vez fixada à uma vara de madeira. A performance consistia, e, persiste ainda hoje, em bater a bexiga com força contra o chão para fazer barulho enquanto os foliões corriam atrás das pessoas que estavam na rua para assustá-las. Atualmente a bexiga boi foi substituída pela bexiga plástica e, por conta disso e da performance, aos poucos, eles ficaram conhecidos como bate-bolas. Hoje os dois nomes coexistem.

Figura 5: Da esquerda para a direita, carnaval 2018: turma de Bate-bolas estilo "bola e bandeira" e turma estilo "sombrinha e leque".
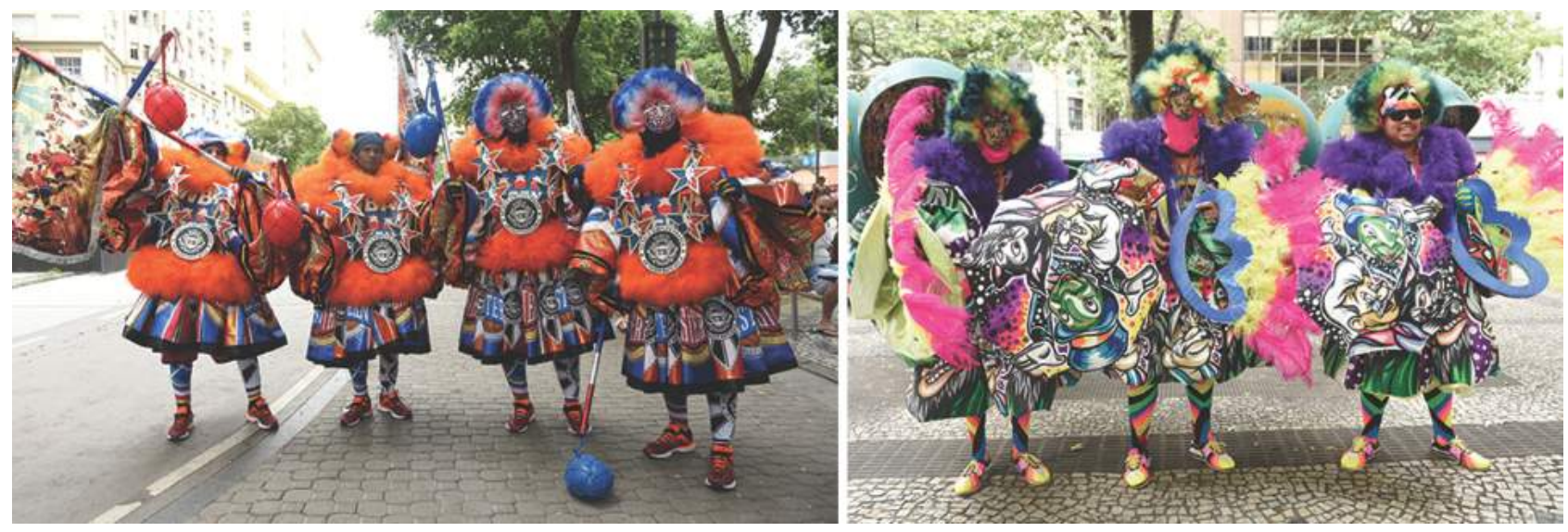

fonte: Ana Paula Moniz, 2018.

Ao longo do tempo, grupos de foliões começaram a formar turmas que hoje podem ser compostas por um número reduzido de integrantes ou até mesmo alcançar cerca de cem componentes, no caso das mais famosas. O termo Clóvis foi caindo em desuso e aos poucos o termo Bate-bolas passou a ser mais empregado. Hoje, estima-se que existam mais de 400 turmas nos bairros suburbanos do Rio de Janeiro. Quando as turmas começaram a se formar, já nos anos 1980, os componentes eram exclusivamente masculinos e majoritariamente adultos. Algumas razões podem ser levantadas para explicar essa afirmação. O preço elevado da fantasia, que ao longo do tempo foi ficando cada vez mais elaborada e consequentemente menos accessível, limitou a participação de crianças ou adolescentes, pois tratando-se de manifestantes com baixo poder aquisiti- 
vo, um pai que financia sua própria fantasia, na maior parte das vezes, não tem condições financeiras de custear também para seus filhos. Além disso, existia rivalidade entre as turmas e poderiam ocorrer episódios violentos, o que fazia com que os homens não permitissem a participação das mulheres e crianças, consideradas mais frágeis e indefesas.

A dissertação de Aline Pereira é de 2008, naquela época era notável a presença masculina, com raras turmas admitindo a presença de crianças e mulheres. (PEREIRA, 2008, p. 50) No entanto, quando os autores deste trabalho começaram a pesquisa de campo (no início de 2017) logo perceberam que o cenário se modificou ao longo desse tempo. A intervenção urbana vem conquistando mais e mais adeptos. Durante esse período, não podemos afirmar que a cidade tenha ficado mais pacífica ou que os subúrbios tenham recebido mais atenção e infraestrutura do poder público. Mas, por outro lado, novas tecnologias ficaram mais disponíveis. Hoje, é muito mais acessível o uso de smartphones ou um computador, ambos ligados à internet. Em conversa com um Bate-bola ele disse acreditar que as redes sociais, primeiro Orkut e atualmente Facebook, aproximaram as turmas de brincantes e facilitaram a comunicação entre elas. Paralelamente, o uso do aplicativo de telefone celular Whatsapp, que permite grupos de conversa, também colabora para esta aproximação. Sendo assim, as plataformas digitais potencializaram a interação entre as diversas turmas que podem, facilmente, compartilhar informações e resolver questões antes problemáticas e que originavam os conflitos. A convivência entre as turmas no espaço urbano durante os festejos do Carnaval e também em eventos ao longo do ano passou a ser muito maior do que foi outrora e, também, muito mais pacífica.

Aliada a essa transformação importante, a presença feminina vem se tornando frequente nesta intervenção, ainda que em quantidade muito menor do que a dos brincantes homens. Isso se deve, possivelmente, às razões apontadas anteriormente, como o decréscimo da violência entre as turmas, e, em consequência, a crescente popularidade da manifestação. Um reduzido número de mulheres participa das turmas tradicionais e vestem a indumentária igual a dos homens. Mas, no geral, as mulheres optaram por formar suas próprias turmas. Entre essas, percebe-se que a grande maioria das turmas femininas estão ligadas às turmas masculinas e seus nomes deixam isso, de certa forma, explícito.

Alguns nomes das turmas masculinas e femininas podem, e devem, confirmar nossa hipótese: Fascinação e Fascinets, Relíkia e Reliketts, Arrastão e Arratets, Superação e Superets. Todas essas empregam o afixo - "ete" (ou tem a mesma sonoridade com grafia diversa) para formar a palavra que designa a turma feminina, assim como esta forma de construção também serviu para gerar o nome Bate-bolete, derivado de Bate-bolas. Ao mesmo tempo, existem outras turmas que não empregam o afixo - "ete" para nomear a turma feminina. A título de exemplificação citamos os Bem-feitos e as Bem-feitas, e as turmas mistas Animação e Pura Tentação. Há ainda turmas femininas sem qualquer ligação com turmas masculinas como as Devassas e as Palhacinhas, mas estas ocorrem em número muito reduzido comparativamente.

Ainda que a inspiração para gerar os nomes das turmas femininas tenha origem nas palavras "chacrete" ou "tiete", que designam dançarinas, assistentes de palco, ou as fãs de uma celebridade, é bastante imediata a associação destes nomes com a depreciação feminina. Mesmo que não façam alusão direta a práticas comportamentais não aceitas socialmente, é possível afirmar que portam um caráter semântico de submissão da turma feminina, de não igualdade entre os gêneros e do desempenho secundário da mulher à sombra do homem. $E$, no caso da palavra Batebolete, por uma sonoridade muito próxima da palavra boquete é muito direta a associação a esta 
prática sexual considerada tabu pela sociedade e que, por isso, ainda deixa margem para outros tipos de associações semânticas da mulher como objeto e introduz a questão sensual que não é presente na manifestação dos Bate-bolas.

Figura 6: Da esquerda para a direita, carnaval 2018:

turma Art Mania, estilo "bola e bandeira", e turma de Bate-boletes Arteiras

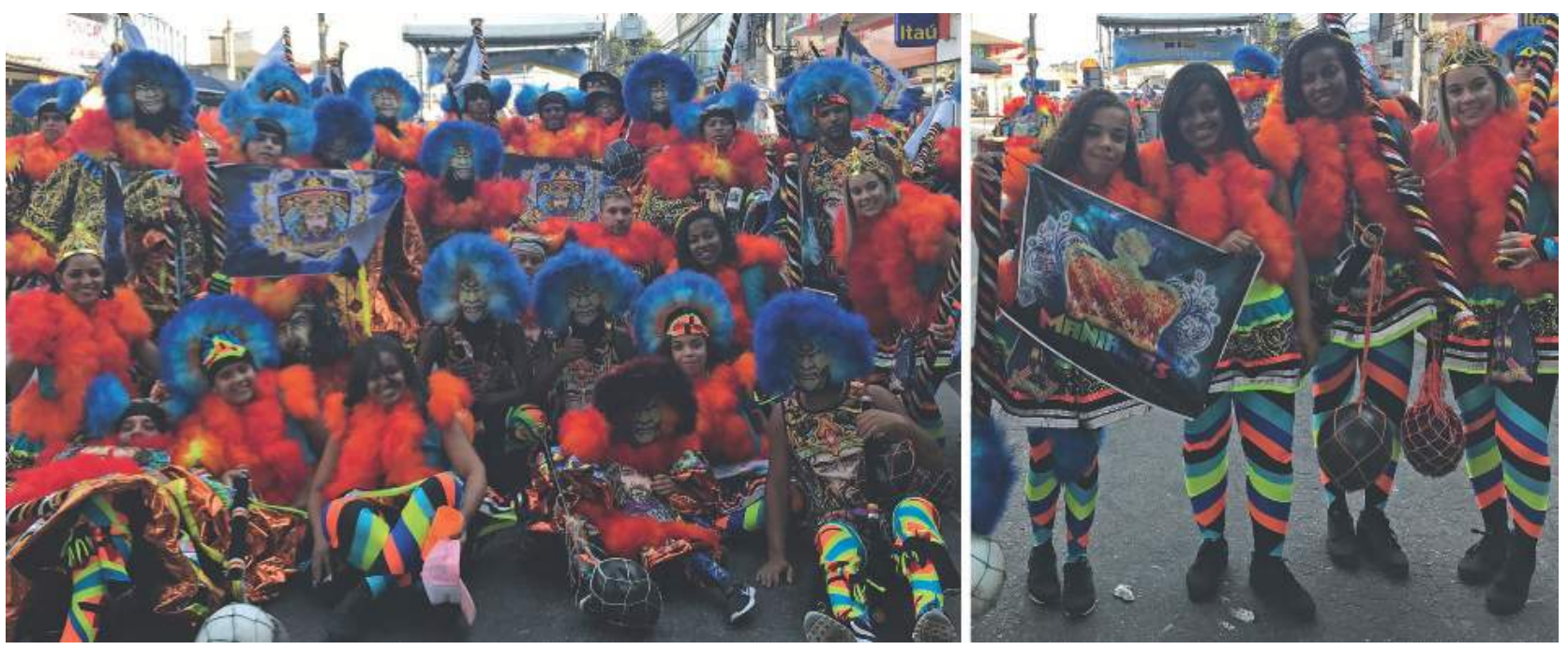

fonte: Priscila Andrade, 2018.

Com relação à caracterização dos foliões do Rio de Janeiro nota-se uma grande diferença entre a indumentária usada majoritariamente por homens e aquela usada por mulheres. No caso da fantasia de Bate-bolas, homens e raras mulheres de poucas turmas usam sempre um macacão volumoso, uma casaca, uma máscara telada que cobre todo o rosto e uma peruca. Estes elementos podem variar bastante em modelagem, cores, desenhos, estampas e materiais. Além disso, os adereços e acessórios que compõem a fantasia podem incluir: sapatilha ou tênis, capa, bola, bandeira, sombrinha, bicho de pelúcia, luvas, meias e etc. A presença deles depende do estilo da fantasia. Como os Bate-bolas são mais antigos que as Bate-boletes, ao longo do tempo foram surgindo variações, sendo as duas principais conhecidas como: "bola e bandeira" e "bicho e sombrinha". Essa última surgiu nos anos 1980 com o propósito de desvincular da fantasia a performance agressiva do bater a bola (PEREIRA, 2008, p. 31). O estilo conhecido como "bicho e sombrinha", por vezes carrega um bicho de pelúcia relacionado ao tema da fantasia anual, mas também pode carregar um estandarte ou um leque, acessório das turmas mais tradicionais. Embora sejam acessórios antagônicos, de acordo com o significado que possuem para os Bate-bolas, é possível também observar, raras vezes, em uma mesma fantasia a bola e a sombrinha (PEREIRA, 2008, p. 88).

Para as mulheres, no caso da fantasia das Bate-boletes, é imprescindível a presença da bola como acessório de sua indumentária para que sejam nomeadas assim. Na ausência desse acessório os foliões nomeiam a indumentária simplesmente como "fantasia feminina". A indumentária da Bate-bolete é descrita pelos foliões como mini Bate-bola, pois as peças que a compõe são menores e mais delicadas. Em observação de campo, no Carnaval de 2018, e analisando fotografias de carnavais anteriores, disponíveis em páginas de turmas no Facebook, observamos uma frequência do uso de minissaias, maiôs, quase sempre com recortes vazados que deixam a pele à 
vista, meias e luvas decoradas. Na cabeça, as mulheres podem usar algum acessório de acordo com o tema da fantasia como, por exemplo: laço, arranjo, penas, coroa, etc. E, a característica que mais nos chama atenção é o fato de que as mulheres Bate-boletes não usam a máscara característica que cobre todo o rosto dos Bate-bolas. Elas fazem questão de apresentar seus rostos maquiados e também dão atenção especial para as unhas decoradas de acordo com o tema da fantasia. Deixam claro o desejo de valorizar e expor seus corpos, conferindo visibilidade e sensualidade ao gênero feminino.

O grupo social do qual fazem parte os Bate-bolas e as Bate-boletes é fortemente ligado à cultura do funk carioca. Tanto que embora suas performances ocorram no carnaval, festejo que é tradicionalmente associado ao samba como gênero musical, nas "festas de Bate-bolas" a música que toca é o funk. Sendo assim, esta pesquisa dialoga com os estudos da antropóloga Mylene Mizrahi que pesquisa a "estética do funk carioca". Concordamos com ela, que emprega a palavra estética não como juízo de gosto, e, sim como referência à forma, "seja ela demarcadora das imagens visuais, verbais ou artefatuais encontradas na aparência física, nas roupas, nos cabelos, no ritmo e nas letras de músicas." (MIZRAHI, 2014, p.19) E, identificamos que a oposição de gênero que se reflete no repertório estético dos homens e das mulheres do "baile funk", tal como analisada por Mizrahi, é também percebida na caracterização de Bate-bolas e Bateboletes. No baile funk, mulheres usam enorme variedade de modelos de roupas, mas todos quase sempre em tecidos com fios elásticos que permitem, ao mesmo tempo, mobilidade para a dança e ajuste ao corpo, valorizando, assim, as curvas da anatomia e colaborando para uma performance de sedução. Já os homens tem dois estilos, os "funkeiros" que se inspiram nos "surfistas" e os que se inspiram no "bombados" (que trabalham os corpos em academias de ginástica). Ambos vestem, em oposição a estética feminina, roupas confortáveis, porém largas, de modo a "preencher o contorno de corpos finos e angulosos que ao dançar, realizam movimentos retos e vigorosos." (MIZRAHI, 2007, p. 242).

Figura 7: Da esquerda para a direita, fotos do carnaval 2018: dupla de Bate-bolas da turma Tolerância Zero, grupo de Bate-boletes da Turma Intoleradas, e foto individual de uma bate-bolete da mesma turma.
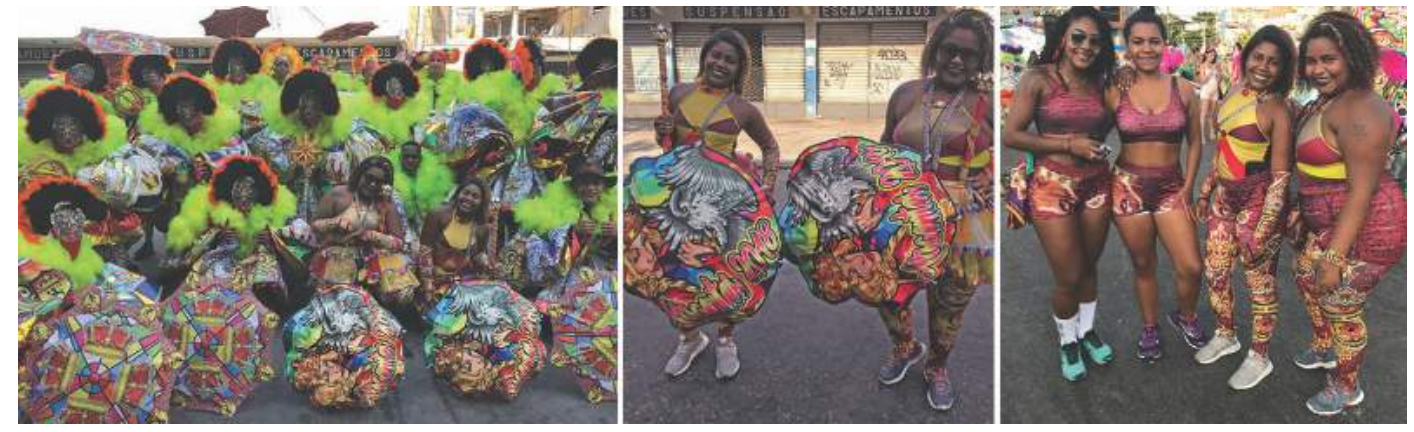

Fonte: As duas primeiras fotos: Priscila Andrade, 2018 / terceira, página de Facebook: Planeta Bate-bola.

O contraste descrito por Mizrahi entre as roupas masculinas e femininas usadas no baile funk com forte oposição entre largo e justo, é igualmente identificado na indumentária dos Bate-bolas e das Bate-boletes, e pode ser entendido como um prolongamento do gosto estético do grupo social aqui estudado. 


\section{Considerações finais}

O quadro abaixo apresenta características das manifestações culturais analisadas neste trabalho. Nosso foco principal é demonstrar como essas manifestações estabelecem a visibilidade e/ou a invisibilidade do gênero feminino. Por isso, em ambos os rituais, nos chamou a atenção o modo como se dá a inserção das mulheres, como elas realizam as performances e como se representam visualmente.

Quadro 1 - comparação entre as manifestações culturais e respectivos brincantes.

\begin{tabular}{|c|c|c|}
\hline \multicolumn{3}{|c|}{ Caretos de Podence } \\
\hline & Participação masculina & Participação feminina \\
\hline Caretos & & \\
\hline Origem & Está na origem; & Recente; \\
\hline Proporção & $\begin{array}{l}\text { Participação majoritária com permissão para } \\
\text { poucas participações femininas; }\end{array}$ & Participação rara (ano passado apenas uma); \\
\hline Performance & $\begin{array}{l}\text { Ligada ao Gênero - Caretos homens chocalham } \\
\text { mulheres e batem com a cauda do capuz em } \\
\text { outros homens. Não chacoalham as Matrafonas. } \\
\text { O cortejo se dá ao som de gaitas e foles tocadas } \\
\text { por músicos que acompanham o desfile. }\end{array}$ & $\begin{array}{l}\text { Ligada ao Gênero - Caretos mulheres não choca- } \\
\text { Iham outras mulheres; }\end{array}$ \\
\hline
\end{tabular}

Não permite a identificação de gênero, mas pressupõem um brincante masculino. Como as máscaras são individualizadas, apenas indivíduos da comunidade e brincantes sabem identificar quem é o mascarado e, portanto, seu

Fantasia gênero. Máscaras de couro ou zinco. Roupa Idêntica à dos homens; confeccionada a partir de colchas antigas, nas quais são aplicadas franjas de lã em listras nas cores verde, amarelo e vermelho. O mesmo tratamento franjado é dado ao capuz que cobre a cabeça e que possui uma longa cauda;

\begin{tabular}{lll}
\hline $\begin{array}{l}\text { Duração } \\
\text { da fantasia }\end{array}$ & $\begin{array}{l}\text { llimitada. Herdada de pai para filho. Quando } \\
\text { desgastada passa por reparos; }\end{array}$ & Idêntica à dos homens; \\
\hline $\begin{array}{l}\text { Criação } \\
\text { da fantasia }\end{array}$ & $\begin{array}{l}\text { Se mantém a mesma desde a origem, não sen- } \\
\text { do reconhecida sua autoria; }\end{array}$ & Idêntica à dos homens; \\
\hline $\begin{array}{l}\text { Confecção } \\
\text { da fantasia }\end{array}$ & Produção familiar; & Idêntica à dos homens; \\
\hline Matrafona & Está na origem; & Recente; \\
\hline Origem & Participação equivalente; & Participação equivalente; \\
\hline Proporção & Acompanham o cortejo dos Caretos pelas ruas; & Idêntica à dos homens; \\
\hline Performance & $\begin{array}{l}\text { Rostos cobertos por rendas e cabeça coberta } \\
\text { por lenço ou chapéu. As roupas lembram }\end{array}$ & Idêntica à dos homens, incluindo enchimentos \\
\hline $\begin{array}{l}\text { Fantasia } \\
\text { vestes femininas camponesas antigas e fora }\end{array}$ & $\begin{array}{l}\text { pe uso. Usam enchimentos para simular o } \\
\text { corpo feminino; }\end{array}$ & Idêntica à dos homens; \\
\hline $\begin{array}{l}\text { Duração } \\
\text { da fantasia }\end{array}$ & Ilimitada. & Idêntica à dos homens; \\
\hline $\begin{array}{l}\text { Criação } \\
\text { da fantasia }\end{array}$ & Improvisada com roupas antigas; & Idêntica à dos homens; \\
\hline $\begin{array}{l}\text { Confecção } \\
\text { da fantasia }\end{array}$ & Roupas preexistentes; & \\
\hline
\end{tabular}




\section{Bate-bolas do Rio de Janeiro}

\begin{tabular}{lll} 
& Participação masculina & Participação feminina \\
\hline Bate-bola & & \\
\hline Origem & Está na origem; & Recente; \\
\hline Proporção & $\begin{array}{l}\text { Exclusiva na maioria dos grupos e participação } \\
\text { majoritária nos poucos grupos mistos; }\end{array}$ & Participação rara em grupos mistos; \\
\hline
\end{tabular}

Independe de gênero: a saída envolve um desfi-

le dançante. No caso dos grupos de bexiga/bola

Performance existe o objetivo de assustar a plateia ao bater

Idêntica à dos homens; a bola com força contra o chão, realizando barulho intenso;

Não permite identificação de gênero, mas pressupõem um brincante masculino. Máscaras teladas pintadas, coletes e macacão bufante sobre meias calças e luvas de malha. Nos pés, tênis ou sapatilha. Exceto o tênis de marca que

Fantasia deve combinar com o resto, todos as peças do

Idêntica à dos homens; vestuário são produzidos de acordo com o tema anual, determinado pela turma. Uso de materiais, cores e formas diversas, dependendo do tema e do estilo de Bate-bola. (bicho e sombrinha, bexiga e bandeira, bujão, capa);

\begin{tabular}{ll}
\hline $\begin{array}{l}\text { Duração } \\
\text { da fantasia }\end{array}$ & $\begin{array}{l}\text { É confeccionada uma nova fantasia a cada ano. } \\
\text { da ou vendida; }\end{array}$ \\
\hline $\begin{array}{l}\text { Criação } \\
\text { da fantasia }\end{array}$ & Projetada pelo cabeça da turma; \\
\hline $\begin{array}{l}\text { Confecção } \\
\text { da fantasia }\end{array}$ & $\begin{array}{l}\text { Pode ser produzida por integrantes da turma, } \\
\text { ou ter produção total ou parcial terceirizada. } \\
\text { dos à mulheres. }\end{array}$ \\
\hline Bate-bolete & $\begin{array}{l}\text { Recente participação apenas de gays masculi- } \\
\text { nos. }\end{array}$ \\
\hline Origem & $\begin{array}{l}\text { Participação rara, exclusivamente de gays mas- } \\
\text { culinos; }\end{array}$ \\
\hline
\end{tabular}

Idêntica à dos homens;

Idêntica à dos homens;

Idêntica à dos homens;

Performance Idêntica à das mulheres;

Está na origem;

Turmas exclusivas com mulheres, sendo raras as turmas independentes e a maioria com ligação a uma turma masculina;

Dançam com algumas das expressões tipicamente de brincante e com interação com a plateia e com os bate-bolas;

Sem máscaras. Uso de peças curtas e justas, relação tanto com o universo do carnaval como com

Fantasia Idêntica à das mulheres; o do funk. Aparência final permite identificação do gênero feminino e exposição e valorização do corpo;

\begin{tabular}{lll}
$\begin{array}{l}\text { Duração } \\
\text { da fantasia }\end{array}$ & Idêntica à das mulheres; & $\begin{array}{l}\text { É confeccionada uma nova fantasia a cada ano. } \\
\text { Ao fim do festejo a fantasia é descartada, doada } \\
\text { ou vendida; }\end{array}$ \\
$\begin{array}{l}\text { Criação } \\
\text { da fantasia }\end{array}$ & Idêntica à das mulheres; & $\begin{array}{l}\text { Projetadas pelas cabeças de turma. Submetidas, } \\
\text { quando ligadas a uma turma masculina, a aprova- } \\
\text { ção do cabeça da turma dos Bate-bolas; }\end{array}$ \\
\hline $\begin{array}{l}\text { Confecção } \\
\text { da fantasia }\end{array}$ & Idêntica à das mulheres; & $\begin{array}{l}\text { Pode ser produzida por integrantes da turma, ou } \\
\text { ter produção total ou parcial terceirizada. Em }\end{array}$ \\
\hline
\end{tabular}


geral os serviços de costura são demandados à mulheres.

Fantasia feminina

*Em todos os itens há uma manifestação idêntica a das Bate-boletes. A grande diferença é que não portam nunca o acessório bexiga/bola.

No caso das mulheres que participam do ritual dos Entrudos Chocalheiros, em Podence, elas acabam por se transvestirem de rapazes, uma vez que, ao cobrirem o corpo com o traje e o rosto com a máscara, ambos herdados ou emprestados de algum familiar homem, nada pode defini-las como mulheres.

O uso das máscaras pelas mulheres resulta na invisibilidade de gênero. Porém, no caso das Bate-boletes, a não utilização de máscaras e a indumentária que coloca em evidência as formas do corpo feminino, acaba por fornecer o que entendemos por uma hipervisibilidade de gênero. Em contrapartida, as máscaras e as fantasias dos Caretos de Podence transformam as pessoas em um único gênero, 0 masculino, uma vez que, por tradição, se trata da "festa dos rapazes".

\begin{abstract}
Mas é justamente a "invisibilidade" do género de quem enverga a máscara que pode criar "um problema de género", pois a função e o papel são cumpridos por corpos sem género. Se entendermos o género como o resultado de performances repetidas e habituais que criam corpos e pessoas codificados como "masculinos" e "femininos" e não como essências biológicas, perceberemos o potencial perturbador do vestir uma máscara que oculta esse código. (ALMEIDA, 2016. p. 69)
\end{abstract}

Ou seja, as mulheres em Portugal, ao vestirem as fantasias dos Caretos e utilizarem as máscaras típicas do grupo acabam por se "transvestirem" de rapazes, uma vez que os ritos invernais de mascarados em Portugal são, culturalmente, um rito destinado ao gênero masculino. Porém, mesmo ao se "transvestirem" de rapazes, estão "rompendo" com regras, pois se inserem num mundo dito masculino. No entanto, mesmo rompendo com as regras, não ganham visibilidade.

É importante sinalizar uma grande diferença: os Caretos de Podence são um único grupo e seus trajes são passados de pai para filho, sendo restaurados ao longo do tempo para que possam ser anualmente usados, como já foi dito anteriormente. Diferente da manifestação dos Bate-bolas e Bate-boletes, que é formada por centenas de turmas que a cada ano criam toda uma nova indumentária, a partir de um tema de inspiração inédito - o que gera um nível muito maior de atualização formal nos bate-bolas e de conservação folclórica nos Caretos.

No caso das turmas de Bate-boletes ligadas a turmas masculinas, as mulheres desenvolvem seus trajes somente após o "tema" ser previamente escolhido pelo grupo de Bate-bolas a que estão associadas. Além disso elas tem que aguardar o traje masculino ficar pronto ou ao menos praticamente todo projetado, para que possam começar a desenvolver suas próprias fantasias em harmonia visual e temática com o que os homens decidiram. É nesse momento, então, que elas tem a relativa autonomia de projetar o traje que fornece a visibilidade feminina de seus corpos pelo uso de roupas coladas ao corpo, mini saia e ausência de máscara que cubra seus rostos. Podem, também, dar atenção especial à maquiagem, penteados e unhas decoradas para, igualmente, promover a visibilidade do feminino.

Provavelmente seja interessante, para um trabalho futuro inserido no campo dos estudos de gênero, uma investigação que verifique até que ponto uma mulher ao se transvestir de rapaz utilizando uma fantasia absolutamente masculina, pode significar uma rebeldia, uma libertação, 
uma adequação, ou mesmo uma subordinação ao mundo masculino. Se os rapazes "chocalham" as moças encenando uma cópula, o que as moças fazem com seus chocalhos? Uma vez transvestidas de rapazes quem vão "chocalhar"?

No caso das Bate-boletes encontramos uma cena bastante diferente. As meninas ligadas aos grupos dos Bate-bolas não se transvestem de rapazes, pelo contrário, a sua indumentária confere visibilidade ao gênero feminino. Na verdade o que ocorre é a hipervisibilidade do gênero uma vez que as fantasias evidenciam o corpo, com as formas curvilíneas atribuídas ao feminino. Além disso, elas não usam máscaras.

Os estudos sobre os Bate-bolas ainda são muito poucos e sobre as Bate-boletes são, praticamente, inexistentes. Com relação à participação das mulheres nos rituais com máscaras em Portugal os estudos existem, mas são muito poucos ainda e necessitam de maior empenho e de maior dedicação. Assim, a relevância desta pesquisa é propiciar um melhor entendimento de como a participação das mulheres em manifestações culturais são passíveis de empoderá-las ou, simplesmente, de mantê-las no estado de submissão - e toda as gamas de variáveis relativas entre essas duas posições absolutas.

\section{Referências}

ALMEIDA, M. V. de. Quando a máscara esconde uma mulher. In: Rituais de inverno com máscara. 1. ed. Bragança, Portugal: Instituto Português de Museus, 2006. p. 61-74.

CANDIDO, B.F.F. (2013) Formações x-ete no português do Brasil: uma análise construcional. Dissertação (Mestrado em Letras Vernáculas) - Programa de Pós-graduação em Letras, Universidade Federal do Rio de Janeiro. Rio de Janeiro, 2013.

COSTA, L. F. R. da. Caretos de Podence: história, patrimônio e turismo. Dissertação (Mestrado em Arte e Patrimônio) - Faculdade de Letras, Universidade de Coimbra. Coimbra, 2015.

FERREIRA, Hélder (coordenação). Rituais com máscara: rota das máscaras em Portugal: Macedo de Cavaleiros. 1 ed. Santo Antão do Tojal, Portugal: Projestur, 2016.

FORMIGA, S. As fôrmas da forma: um estudo da (des)configuração dos corpos português e brasileiro. In: CIMODE - 10 Congresso Internacional de Moda e Design. Guimarães: Escola de Engenharia da Universidade do Minho, 2012.

GUALDA, A.V.V.P. e FERREIRA, L.F. Turmas de bate-bolas do carnaval contemporâneo do Rio de Janeiro: diversidade e dinâmica. Visualidades, [S.I.], v. 7, n.ㅇ 2, abr2012.

GUALDA, A.V.V.P. Tramas simbólicas: a dinâmica das turmas de bate-bolas do Rio de Janeiro. Dissertação (Mestrado em Artes) - Instituto de Artes, Universidade do Estado do Rio de Janeiro. Rio de Janeiro, 2008.

MIZRAHI, M. A estética funk carioca: criação e conectividade em Mr. Catra. 1. ed. Rio de Janeiro: 7 Letras, 2014.

MIZRAHI, M. O figurino funk e a sedução: a roupa, o corpo e a dança na esfera da festa.Interseções [Rio de Janeiro], Vol. 11, n. 1, p.149-171, jun2009.

MIZRAHI, M. Indumentária funk: a confrontação da alteridade colocando em diálogo o local e o cosmopolita. Horizontes Antropológicos, Dez, vol. 13, n.ㅇ 28, p.231-262, 2007. 
PEREIRA, Benjamin (Coordenador Científico). Rituais de inverno com máscara. 1. ed. Bragança, Portugal: Instituto Português de Museus, 2006.

RAPOSO, P. "Caretos" de Podence: um espetáculo de reinvenção cultural. In:Rituais de inverno com máscara. 1. ed. Bragança, Portugal: Instituto Português de Museus, 2006. p. 75-100.

Tiza. A. A. P. O Carnaval de Podence, 2018. In: Academia Iberamérica da Máscara.

(http://academiaibericamascara.org/index.php/pt/estudos/74-o-carnaval-de-podence)Acessado em: 29 de março de 2018. 